\title{
Mothers Experience about Complementary Feeding Practice in Bangladesh
}

\author{
Kuntala Gain ${ }^{1}$, Shanzida Khatun ${ }^{2}$, Md. Sazzad Hossain², Dipali Rani Mallick ${ }^{2}$ \\ ${ }^{1}$ Shaheed Tajuddin Ahmad Nursing College, Gazipur, Dhaka, Bangladesh \\ ${ }^{2}$ National Institute of Advanced Nursing Education and Research (NIANER), Dhaka, Bangladesh \\ Email:k.rani.db@gmail.com, sanzidaadib@yahoo.com
}

How to cite this paper: Gain, K., Khatun, S., Hossain, M.S. and Mallick, D.R. (2020) Mothers Experience about Complementary Feeding Practice in Bangladesh. Open Journal of Pediatrics, 10, 423-437. https://doi.org/10.4236/ojped.2020.103043

Received: June 23, 2020

Accepted: August 17, 2020

Published: August 20, 2020

Copyright $\odot 2020$ by author(s) and Scientific Research Publishing Inc. This work is licensed under the Creative Commons Attribution International License (CC BY 4.0).

http://creativecommons.org/licenses/by/4.0/

\begin{abstract}
Background: Complementary feeding is a significant milestone that has nutritional, developmental, and health implications. Worldwide, $33 \%$ of the deaths are linked to malnutrition. Objective: To describe the mothers' experience about complementary feeding practice with child aged less than two years in Bangladesh. Method: A descriptive qualitative study was conducted from July 2018 to June 2019. This study was approved by the Institutional Review Board (IRB) NIANER. 20 mothers of children of 6 - 24 months of age were recruited purposively who live in Sattalla slum. Descriptive statistics were used to analyze the mothers' demographic characteristics and thematic analysis was used to describe mothers' experience about complementary feeding practice. Results: The study showed that the average age of the mothers was 25 ( $\mathrm{SD}=4.75)$ years. Only $5 \%$ of the mothers have higher education. Through the findings, two main themes have been identified. Moreover, first main theme includes three subthemes. Fifty percent of the mothers stated that appropriate time to start complementary food for their babies is from 6 months of age. Mothers feed various types of complementary foods. Most of the mothers have knowledge about complementary feeding but they do not practice appropriately. Almost all of the mothers (95\%) stated that their babies do not like to eat anything, and $45 \%$ of mothers feed only breast milk. Conclusion: Findings of the study will provide information for the nurses resulted in increasing the rate of complementary feeding practice among mothers of children in Bangladesh. Future study is needed to identify the factors influencing complementary feeding practice among mothers of 6 24 months old children in Bangladesh.
\end{abstract}

\section{Keywords}

Experience, Complementary Feeding, Practice, Mothers, Children 


\section{Introduction}

\subsection{Background}

The introduction of solid food to infants' diets, known as complementary feeding, is a significant milestone that has nutritional, developmental, and health implications [1]. According to the World Health Organization's (WHO) recommendation, exclusive breastfeeding will be until six months, with introduction of solid food after six months [2]. After six months, breast milk alone is no longer sufficient to meet late infant's nutritional requirements [3]. Timely starting nutritionally-adequate, safe, age appropriate complementary feeding at sixth month of age is recommended for better health and development of infants [4].

Complementary feeding enables infants to meet their nutritional requirements and regulate their appetite, whilst becoming exposed to new tastes and textures in a staged and progressive manner [1]. Insufficient quantity and inadequate quality of complementary foods, together with poor feeding practices and increased rates of infection during this period are direct risk factors for stunting [5] [6]. Breastfeeding and weaning practices are important elements of growth and development not for infancy as well as later in life. Poor infant-feeding practice can lead to stunted growth, delayed motor and mental development, immune incompetence, and increased risk of infectious diseases such as diarrhea [7].

In Bangladesh, the rate of under-five mortality is 5.6 million per year among them malnutrition is the leading cause of the mortality [3]. A study found that, only $71 \%$ of infants consume soft, semi-solid and solid food by 6 - 8 months of age. The study also revealed that mothers who had no education had a higher risk of not introducing complementary foods timely [8]. Worldwide, 6.9 million children below the age of five years died in 2011 and 33\% of the deaths were linked to malnutrition [9]. Globally, about half (52\%) of children aged $6-23$ months meet the minimum meal frequency and less than one third $29 \%$ meet the minimum dietary diversity, with large disparities across and within regions [10]. Malnutrition is directly or indirectly responsible for $60 \%$ of the 10.9 million deaths annually of children less than 5 years old [11] [12]. Inappropriate feeding practice attributes to over two-third of these deaths, and occurs during the period of infancy [13]. Appropriate complementary feeding has the potential to prevent $6 \%$ of all "under 5 deaths" particularly in developing countries [13].

After six months, breast milk alone is no longer sufficient to meet late infants' nutritional requirements and for that reason, timely starting of nutritionally-adequate, safe, age appropriate complementary feeding at sixth month of age is recommended for better health and development of infants [4]. The first two years of life are critical for a child's growth and development because of damage caused by nutritional deficiencies during this period which leads to impaired cognitive development, compromised educational achievement and low economic productivity [14]. The causes of childhood malnutrition in young children are low birth weight and high morbidity as well as inappropriate practices 
such as the delayed introduction of complementary foods, low energy and nutrient density of foods offered, feeding in small amounts at meals, and food restrictions due to cultural beliefs even in parts of Southeast [12] [15]. Infant and young child feeding practices (IYCF) directly impact the nutritional status and, ultimately the survival of children under 2 years of age [16]. Therefore, improving infant and young child feeding is critical to ensure their optimal health, nutrition and development [17]. Complementary feeding includes a complex set of behavior and decisions, which are in turn influenced by the caregiver's knowledge and skills, time constraints, social support system and community context [8]. In addition, minimum feeding frequency and minimum dietary diversity are suboptimal even in households from higher wealth quintiles, suggesting that other factors such as cultural practices, traditional beliefs, and poor knowledge regarding adequate diets for young children need to be addressed [18].

In Bangladesh, there are some descriptive studies on complementary feeding practice, factors influencing complementary feeding, mothers perception of weaning, mothers knowledge and practice regarding complementary feeding among mothers and infant, Barrier [9]. However, most of the studies are quantitative study. There is a limited research in depth regarding mothers' experience about complementary feeding practice. Qualitative research seeks to describe and analyze the culture and behavior of human from the participants' point of view. It aims to obtain a comprehensive understanding of the context and the social behavior. Qualitative research and strategies are flexible and iterative, meaning that research questions can be changed or altered during the course of the study. This flexible approach may help discover unexpectedly important topic in Bangladesh. This qualitative research focuses more on providing information for the nurses in Bangladesh.

\subsection{Objective}

The study intends to describe Bangladeshi mothers' experience about complementary feeding practice who have children aged less than two years.

\section{Methods}

\subsection{Study Design}

A descriptive qualitative study was conducted to explore the mothers experience of complementary feeding practice. Qualitative research seeks to describe and analyze the culture and behavior of humans from the participants point of view.

\subsection{Study Participants}

The participants of the study were mothers who have children aged 6 - 23 months of children living in Sat Tala Slum in Dhaka City. Approximately twenty (20) mothers were selected purposively who met the inclusion criteria. The inclusion criteria of the mothers were:

- Mothers living in Sattala Slum, Mahakhali, Dhaka. 
- Having child aged 6 - 23 months.

\subsection{Instruments}

A semi-structured interview guideline was used for data collection developed by the researcher. The demographic data questionnaire included 11 items such as mothers age, educational level, occupation, family income, housing status, age during marriage, antenatal visiting (times), child's age, number of children, sources of information regarding complementary feeding, sex, body weight. Interview questions were developed regarding complementary feeding. The contents of the interview guiding questions were validated by three experts including two Ph.D. holder nurses and a medical doctor. The interview guiding questions are as follows:

1) Greeting and introductory question

2) Transition question:

Explain the ground rules for research and purpose.

3) Key Questions:

a) Could you explain about complementary feeding?

b) Could you tell me about the benefits of complementary feeding for your child?

c) Could you know about the weaning guideline?

If yes, then could you explain about the weaning guideline?

d) What is your opinion about advantage and disadvantage of complementary food?

e) Could you tell me when complementary food should start for your child? Why from where and whom did you get this information?

f) Based on your understanding or knowledge what are the possible foods for your child?

g) Could you tell me what kind of complementary food you let to eat your child?

h) Could you tell me about the process of making complementary food for your child?

\subsection{Data Collection}

After approval from the Institutional Review Board (IRB) of National Institute of Advanced Nursing Education and Research (NIANER) IRB (EXP-NIA-S-2018-25) between December 2018 to January, Permission was taken from the community leader. Mothers were informed about the purpose and process of the study. An introduction of study purpose was given to the mothers and their willingness to participate in the study was taken and data were collected by the researcher through in-depth interview which was all conducted in Bangla language. Caregivers were also provided information about the stud orally both in local language and Bangla language using interview guiding questionnaires focusing on complementary feeding. Informed consent paper was signed by mothers before 
data collection. The participants were assured that confidentiality and anonymity would be maintained. Time duration of interview of each mother was around $1-1.5$ hours. Information was obtained by the researcher using audio recorder and later the recordings were transcribed into written form. If further clarification was needed, especially during interview, the researcher probed or asked the question in their local language. Finally, the information was translated into verbatim in English by the researcher. A small gift was given to the participants as compensation for their time. Finally, the researcher thanked the mothers for their contribution.

\subsection{Data Analysis}

The in-depth interviews were transcribed verbatim in Bengali language by the researcher and professional checked transcripts involving interpretation. On-going analysis took place throughout the research process in the form of a research diary, notes and reflections. Interview data was verified repeatedly listening to the audio tape recorder which involved reading through the transcripts and field notes looking for immerging themes. During the analysis, the notes including nonverbal cues and some meaningful motions of the participants like surprise, pauses, laughter, anger, discomfort and so on were used to help to clarify and complete the record transcribing. Then the transcribed data was translated into English by the researcher. Then coding categories were developed, and data were coded and sorted into code categories. Coding proceeded towards the development of categories, themes or major constructs. The codes were words, expressions, other chunks of data. Researcher used different colored pencil to identify closely linked material. After coding, exploration and selection of themes based on the study groups were completed with the help of chief advisor. Then researcher and thesis advisors read the analyzed data repeatedly to ensure consistency for final reporting.

\section{Result}

This chapter describes the finding of the study variables. The aim of the study was to describe the mothers' experience about complementary feeding practice in Bangladesh. The results of the present study are presented as described by mothers including their Child's characteristics and thematic description of the mothers' experience about complementary feeding practice. The finding of the study has identified two main themes. The first main theme includes three subthemes. 1) Experience of Mothers regarding Complementary feeding. a) understanding of mothers about complementary feeding, b) impact of complementary feeding, and c) source of information regarding complementary feeding; 2) Practice Regarding Complementary Feeding.

\section{Mothers and their Childs Characteristics}

Table 1 shows that average age of mother's were 25 ( $S D=4.75)$ years. All of the mothers were Muslims, two-third of them were literate (75\%). Most of the 
Table 1. Demographic Characteristic of the mothers and their children $(\mathrm{N}=20)$.

\begin{tabular}{|c|c|c|c|c|}
\hline Variable & Categories & $\mathrm{N}$ & $\%$ & $\mathrm{M}(\mathrm{SD})$ \\
\hline \multicolumn{5}{|l|}{ Mothers characteristic } \\
\hline Age (years) & & & & $25.00(4.75)$ \\
\hline Religion & Islam & 20 & 100 & \\
\hline \multicolumn{5}{|l|}{ Education } \\
\hline & Illiterate & 5 & 25.0 & \\
\hline & Literate & 15 & 75.0 & \\
\hline \multicolumn{5}{|l|}{ Occupation } \\
\hline & Housewife & 14 & 70.0 & \\
\hline & Others & 6 & 30.0 & \\
\hline Monthly family income & & & & $16,900(143,26.64)$ \\
\hline \multicolumn{5}{|l|}{ Number of children } \\
\hline & $1-2$ & 14 & $70 \%$ & \\
\hline & $>2$ & 6 & $30 \%$ & \\
\hline \multicolumn{5}{|l|}{ Housing } \\
\hline & Rent & 10 & 50.0 & \\
\hline & Non rent & 10 & 50.0 & \\
\hline Age during marriage & & & & $16.15(2.56)$ \\
\hline \multirow[t]{4}{*}{ Antenatal Visits (times) } & & & & $5.45(3.93)$ \\
\hline & Less than 4 & 6 & 30.0 & \\
\hline & 4 Visit & 7 & 35.0 & \\
\hline & More than 4 Visit & 7 & 35.0 & \\
\hline \multicolumn{5}{|c|}{$\begin{array}{l}\text { Sources of information regarding } \\
\text { complementary feeding }\end{array}$} \\
\hline & Family & 20 & 100 & \\
\hline & Relative & 15 & 75 & \\
\hline & Media & 17 & 85 & \\
\hline & Health worker & 6 & 30 & \\
\hline & Others & 18 & 90 & \\
\hline \multicolumn{5}{|l|}{ Child characteristic } \\
\hline Age & & & & $13.80(4.720)$ \\
\hline \multicolumn{5}{|l|}{ Sex } \\
\hline & Boys & 11 & 55.0 & \\
\hline & Girls & 9 & 45.0 & \\
\hline Gestational age of children & & & & $9.35(0.49)$ \\
\hline Body weight & & & & $9.15(1.95)$ \\
\hline
\end{tabular}


mothers were housewives (70\%) and their average monthly family income was $16,900 \mathrm{TK},(\mathrm{SD}=14,326.64)$ monthly. Majority of mothers (70\%) had $1-2$ children. Half of the mothers (50\%) lived in a rented house. The mean age of the mothers during marriage was 16.15 ( $\mathrm{SD}=2.560$ ) years. Only $30 \%$ mothers completed their antenatal visit less than four times whereas $70 \%$ visited more than 4 times. Mothers received information regarding complementary feeding from different sources. All mothers (100\%) got information regarding complementary feeding from family, whereas relative $75 \%$, media $85 \%$, Health worker $30 \%$, Others $90 \%$. mothers child's mean age was $13.80(\mathrm{SD}=4.720)$ month. The gender distribution of their children is boys $55 \%$ and girls $45 \%$. Gestational age of child were 9.35 (SD = 489) months and mean weight were $9.15(\mathrm{SD}=1.947) \mathrm{kg}$.

Theme 1: Experience of Mothers regarding Complementary feeding

Understanding of mothers about complementary feeding

Among 20 mothers nearly half of the mothers stated that appropriate time to start complementary food of their children is after fulfilling of 6 months age, They feed various complementary food like, khicuri, rice, fruits, fish, egg, vegetables, payes, suji, full cream milk, meat, liver, pumpkin, potato. They think that complementary foods are good for their babies. Health growth, brain development and nutrition can be ensured by these kinds of food. One fourth of mothers stated that appropriate time to start complementary food is below 5 months of age and some mothers stated that they don't know when complementary food should be started. Among them, few numbers of mothers stated that " $I$ think that the appropriate time to start complementary food is after fulfilling the age of 6 months but I started from 3rd month of mybaby". Almost all mothers don't have any idea about the weaning guideline and very few numbers of mothers only heard about weaning guidelines but couldn't explain. Mothers have knowledge about different kinds of complementary foods. Most of the mothers stated that they provide rice, egg and fishes complementary foods. A mother stated that "I don't know when complementary food can be started" (Mother 3). She also said that she started suji at the age of 3 months and khicuri from 6 months of her child. However, others were stated that " $U p$ to 6 th months, only breast feeding should be given, and then khicuri, suji can be given. But honestly, I didn't give any complementary food to my any baby" (Mother 6). "I started giving Suji after the age of one month, khicuri after 3 months, rice was provided from the 5 th month of age" (Mother 16).

A few number of mothers expressed different kinds of opinions regarding starting of complementary feeding like "I know the appropriate time to start complementary food is after fulfilling the age of 6 months but I started from 3 rd month of my baby" (Mother 6, 9, 14). Regarding weaning guidelines, a great number of mothers don't have any idea about the weaning guideline and they provide their Childs' rice, egg and fish as a complementary food.

Impact of Complementary Feeding

Most of the mothers thought that complementary food is beneficial for their 
children in various ways. They also thought that benefits of complementary feeding are, the development of their babies' brain, getting more nutrition, getting a healthy figure, appropriate growth and development and improvement of intelligence, getting more vitamin to grow up day by day. A few mothers stated that "I think only benefit is to fill stomach of my baby. Baby can grow normally and it's doesn't depend on feeding" (mother 9). "I don't know about the benefits of complementary food. Everyone tells me to feed complementary food, so, I am giving" (mother 4). Some of the mothers stated that complementary food fillbaby's stomach and remove hunger in that case frequency of breast feed decreases. They stated that frequency of disturbance of their kids reduces and they play for long time. Around half of the mothers stated a gross benefit mothers stated that "if baby takes complementary food, baby will stay outside fort more time and will play with others. Mothers can do her work keeping her child to anybody".

Most of the mothers stated about the difficulties of giving complementary food. Such as babies do not like to eat anything and so they suffered from vomiting, dysentery, and respiratory distress after giving complementary food. Therefore, they stopped trying complementary feeding. Mothers 5 specified that "I cook khicuri for him. I tried for three days, but my child didn't eat. He only cried and also had possibility to go respiratory tract. Still I tried to feed during cry, but vomiting started. It's very boring that's why I have stopped to feed him" (mother 5). "Most of the time vomiting and dysentery appeared after complementary feeding" (mother 12).

"Feeding of khicuri created diarrhea. That's why I don't feed khicuri. Diarrhea is a problem for me" (Mother 17).

\section{Perceive Source of Information regarding Complementary Feeding}

Almost all mothers got information regarding complementary feeding from family, whereas relative act as a source of information of one third numbers of mothers. Most of the mothers also got information by mass media like television, very few number of mothers got information from health workers at home during home visit and others and very few numbers of mothers have no response about this. Around half a number of the mothers stated that they start complementary feeding their babies after completing the 6 months of age among them and those mothers think that Complementary feeding should be started after fulfilling the age of 6 months because babies will physically good, stomach will full and growth will be increased. Less than half number of mothers know that appropriate time of starting complementary food is after completion of six months of age but they start giving them complementary food even before that age.

Less than half numbers of mothers started giving complementary foods at different time like-some of mothers started 3 months of age of their kids though they know about appropriate time of complementary food, and got information from doctors in hospital but still they start age of three months. "Doctor said, complementary food should be started after completing the age of 6 th months, 
but I have given suji to my baby after the age of 3 months due to family problem" (mother 13).

Another mother also stated that "I have started to feed complementary food from 3rd month as I was a job holder at that time. But I know it should be started after six months. Doctor told me when I visited hospital' (Mother 9). Few mothers expressed their opinion that complementary food should be started after fulfilling the age of 7 months. Among them one mother stated that " $M Y$ baby takes only breast milk. When I went to doctor, he told me to start complementary food after the age of 7 th months. I don't know why complementary food should not be given before 7 th months and why should I give it latter, I know only this that doctor has told so" (Mother 16). Another few number of mothers know about appropriate time to start complementary food she got this information from doctor because her baby was sick that's why she starts late.

Theme 2. Practice Regarding Complementary Feeding

Around one fourth numbers of mothers stated that "I didn't give anything because child dislikes to eat" among them a few numbers of mothers stated that "I don't give her any complementary food because I think, I have sufficient breast milk and it s can fill her stomach" (Mother 6).

One mother stated that "this is not clear to me which type of food I should feed to my baby. I went to doctor as he doesn't eat. But doctor said to feed him khicuri. Doctor also told to not feed him forcefully even he doesn't eat anything by whole day that's why I don't give her any complementary food" (Mothers 5). Around half numbers of mothers stated that rice is main complementary food for their child, with extra food like biscuit, cake, chips like this. Among them few numbers of mothers think that breast milk is essential with rice., fish, firni, Suji, biscuit extra milk, suji and egg and so on will eat .very few numbers of mothers stated that only familial food. Khicuri and some mothers stated that only suji provide their children. And there is no selective food as a complementary food.

Around half of the mothers stated that they start complementary feeding their baby after completing 6 months. And nearly half a numbers of mothers started complementary food for their child below the age of five months and very few numbers of mothers started complementary food after the fulfilling age 7 months.

More than half of the mothers could explain how to cook khicuri. They used different kinds of vegetables dal, rice to prepare kichuri and khicuri was neither dry nor liquid. Around half mothers explained that they cook suji, but among them half of the mothers cooked in inappropriate way. Around one fourth numbers of mothers expressed different kinds of opinion. Some mothers said that they cook noodles by milk, misri and boiled water and egg. Mothers no 6 stated that "I don't cook any complementary food for my baby. I have nothing cook for my baby. He eats rice every day 3 times" (mother 7). Some mothers don't make extra anything for baby. Normally, baby eats their family food and another 5\% stated. "Process of making formula milk used 2 spoon milk in a fider 
$(150 \mathrm{ml})$ of water. For half of fider water, use 1.5 spoon milk" (mother 17).

\section{Discussion}

The purpose of the study is to describe the mothers' experience about "Complementary Feeding Practice" in Bangladesh. A descriptive qualitative study design was conducted to discover insights into complementary feeding experience of mothers of children. The study finding identified two main themes including three subthemes.

\subsection{Demographic Characteristics of the Participants and Their Child's}

The study was conducted among 20 mothers who lived in Sat Tala Slum in Dhaka City. The result showed that the average age of mothers was 25 years. The finding was similar to other studies [4] [19] showed that the mean age of mothers was 26.34 years. Most of the participants were housewives and had formal education. A study conducted in Ethiopia and it found that only five mothers had higher level of education [20]. Most of the mothers were housewives and their average family income was very small when compared with the national average income [21]. The mean age of the mothers during marriage was 16.15 $(\mathrm{SD}=2.560)$ years. Consistent with the study of [22]. According to Bangladesh Law the mean marriage age will be 18 years for female and 21 years for male person. Therefore, this early marriage may influence poor maternal feeding practice [23].

\subsection{Experience of Mothers Regarding Complementary Feeding}

In the present study, half of the mothers had knowledge about appropriate time to start complementary food (after fulfilling of 6 months age) as recommended which is consistent with other study [24]. On the other hand, mothers expressed, one fourth that complementary food should be started at before six months of age which is nearly similar to other study findings conducted in Ethiopia where it was reported that $19.7 \%$ of mothers initiated complementary feeding before the age of six months [4]. In the current study, more than three quarter mothers knew about various types of complementary foods which is supported by other study findings [25]. The current study revealed that only two mothers heard about the weaning guidelines whereas all mothers rated that complementary food is good for their child which is consistent with a study conducted in Finland [24] [26].

The influencing factors of mothers' decision regarding complementary feeding depends on their salient beliefs regarding the advantages and disadvantages of introducing complementary feeding and the influence by importance discussed by others which is congruent with a study where reported mothers' decision influenced by neighbor, relatives health professional as well as their perception regarding the advantages of complementary [26]. In this study, most of the 
mothers think that complementary food is beneficial for their children in various ways like-baby's brain can be built up and they will get more nutrition, appropriate growth and development and improvement of their intelligence. This finding is inconsistent a study conducted in Australia where it was found that a number of mothers did not identify the introduction of complementary feeding as advantageous mothers [25]. The present study found that mothers give complementary food to their children to decreasing the frequency of breastfeeding and feel free to work without any worries regarding their child's hunger. However, almost all mothers told that their baby don't like to eat anything. Consistent with the studies [25] [26] and revealed that most of child did not take any kind of food except breastfeeding.

Very few mothers try to feed their baby by playing mood, while around half of mothers forcefully feed their baby. The fact may be the mothers were not highly educated and unaware about the procedure of feeding and disadvantages of forcefully feeding. Study also revealed that mothers have misperception regarding the complementary feeding such as they think that complementary food responsible for their babies' illness so that they did not like to feed complementary feeding.

Regarding sources of information about complementary feeding almost all of the mothers got information from their family. This finding is consistent with the study of [24] and found that fathers are associated with infant and young child feeding practices. However, other studies found showed that mother got information from friends, family, community, radio, television, health centers and others separately [26] which was dissimilar to the present study. The possible reason may be the mothers of children lived in slum area and all of them were housewives. Therefore, it was difficult to go outside and get information from the health care providers.

\subsection{Complementary Feeding Practice}

Inappropriate feeding practices are often greater determinants of inadequate intakes and child malnutrition and death. Most of the mothers described how they introduced complementary foods to their infants. In this current study, one fourth mothers stated that they didn't give anything because their children dislikeeating. This finding is consistent with the previous study [26]. Mothers of the present study described that rice as the most important complementary food with fish, meat, and vegetable that are practiced as a familiar food consistent with the study of Walsh et al. [25].

The present study discovered that one fourth of mothers started complementary feeding at less than 5 months of age of their kids because of time management as most of the mothers have to manage the household works and they also suffer from insufficient breast milk. It is consistent with a study conducted in South Africa and found that the most common reason for adding foods and liquids to breastfeeding was the perception of inadequate breast milk supply [27]. 
The current study identified that most of the mothers had sufficient knowledge regarding the procedure of making complementary foods but they did not cook regularly for their child. The reasons are child refusal to eat, wastage of food, and limited time to cook/prepare food. The result of the study revealed that of the mothers had positive attitude regarding taking cautions about the food preparation and cleanliness.

The main limitation of this study was the study design as data were collected from only one slum area in Dhaka city and predominantly less educated populations. Therefore, generalization of the results is not ensured if we consider all of the mothers living in Bangladesh. Potential weakness of the study lies in the use of self-report interviewed guidelines to determine maternal infant feeding practice.

\section{Conclusion and Recommendation}

The purpose of the current study was to describe the mothers' experience about complementary feeding practice with child aged less than two years in Bangladesh. Complementary feeding practices are still far from ideal situation in Bangladesh. Many factors affect different aspects of complementary feeding practices. The current study found that almost all mothers have adequate knowledge about the complementary feeding practice but they do not practice it in an appropriate way. Misconception, misbelieves, insufficient breast milk, insufficient family support and mothers occupation act as barriers to practice appropriate complementary feeding followed by pre-lacteal feeding, formula feeding, feeding during sleep and negative attitude of mothers. Neighbors and family members, television health workers influence mothers a lot in case of complementary feeding practice. Educational qualification has positive influence on appropriate feeding practice. Future study is needed to identify the factors influencing complementary feeding among the mothers of $6-24$ months old children in Bangladesh. Findings from the study may provide information for the nurses in increasing the rate of complementary feeding practice among mothers of children in Bangladesh.

\section{Recommendations}

Infant feeding practice has long lasting influence on children's nutrition and health. Therefore, it is an important of the factor identified which is influencing maternal feeding decision as mothers are joining workforce nowadays. Future intervention study is needed. Mothers are interested in any kind of heath behavior if they are advised by the health care provider. So, government and nongovernment organizations should increase their various health-related activities to grow mothers' awareness and practice regarding complementary feeding. Health education interventions are needed to promote exclusive breastfeeding and appropriate complementary feeding practice. Family support is to be strengthened by improving education to family members, especially of mother-in-law 
and husband. Attitude of mothers/caregivers must be changed by repeated counseling starting from antenatal visits. Moreover, it is suggested that improvements in the food grant program are needed to improve the condition of low-income mothers.

\section{Acknowledgements}

First of all, I give thanks to Almighty God for His divine help and providence, strength and letting me capable of completing this study. I would like to express my heart-felt gratitude to the authors of this study. I must give enormous thank to all mothers who participated in this study. My immeasurable gratitude goes out to my husband for his continuous support, encouragement and understanding. Special thanks to my mother for her life time love and support.

\section{Conflicts of Interest}

The authors declare no conflicts of interest regarding the publication of this paper.

\section{References}

[1] Maslin, K., Galvin, A.D., Shepherd, S., Dean, T., Dewey, A. and Venter, C. (2015) A Qualitative Study of Mothers' Perceptions of Weaning and the Use of Commercial Infant Food in the United Kingdom. Maternal and Pediatric Nutrition, 1, 1. https://doi.org/10.4172/2472-1182.1000103

[2] UNICEF Child, Y. (2011) Infant and Young Child Feeding. Nutrition.

[3] UNICEF (2017) Bangladesh's Child Mortality Rate Drops by $73 \%$ in 25 Years.

[4] Shumey, A., Demissie, M. and Berhane, Y. (2013) Timely Initiation of Complementary Feeding and Associated Factors among Children Aged 6 to 12 Months in Northern Ethiopia: An Institution-Based Cross-Sectional Study. Biomedical Central Public Health, 13, 1050. https://doi.org/10.1186/1471-2458-13-1050

[5] Bhutta, Z.A., Das, J.K., Rizvi, A., Gaffey, M.F., Walker, N., Horton, S. and Black, R.E. (2013) Evidence Based Interventions for Improvement of Maternal and Child Nutrition: What Can Be Done and at What Cost? The Lancet, 382, 452-477. https://doi.org/10.1016/S0140-6736(13)60996-4

[6] Danaei, G., Andrews, K.G., Sudfeld, C.R., Fink, G., McCoy, D.C., Peet, E., Fawzi, W.W., et al. (2016) Risk Factors for Childhood Stunting in 137 Developing Countries: A Comparative Risk Assessment Analysis at Global, Regional, and Country Levels. PLOS Medicine, 13, e1002164. https://doi.org/10.1371/journal.pmed.1002164

[7] Lindsay, A.C., Wallington, S.F., Greaney, M.L., Hasselman, M.H., Tavares Machado, M.M. and Mezzavilla, R.S. (2017) Brazilian Immigrant Mothers' Beliefs and Practices Related to Infant Feeding: A Qualitative Study. Journal of Human Lactation, 33, 595-605. https://doi.org/10.1177/0890334416676267

[8] Kabir, I., Khanam, M., Agho, K.E., Mihrshahi, S., Dibley, M.J. and Roy, S.K. (2012) Determinants of Inappropriate Complementary Feeding Practices in Infant and Young Children in Bangladesh: Secondary Data Analysis of Demographic Health Survey 2007. Maternal \& Child Nutrition, 8, 11-27. https://doi.org/10.1111/j.1740-8709.2011.00379.x 
[9] Nankumbi, J. and Muliira, J.K. (2015) Barriers to Infant and Child-Feeding Practices: A Qualitative Study of Primary Caregivers in Rural Uganda. Journal of Health, Population, and Nutrition, 33, 106.

[10] White, J.M., Bégin, F., Kumapley, R., Murray, C. and Krasevec, J. (2017) Complementary Feeding Practices: Current Global and Regional Estimates. Maternal \& Child Nutrition, 13, e12505. https://doi.org/10.1111/mcn.12505

[11] Mekbib, E., Shumey, A., Ferede, S. and Haile, F. (2014) Magnitude and Factors Associated with Appropriate Complementary Feeding among Mothers Having Children 6-23 Months-of-Age in Northern Ethiopia; A Community-Based Cross-Sectional Study. Journal of Food and Nutrition Science, 36, 5-8. https://doi.org/10.11648/j.jfns.20140202.13

[12] Kinoti, F.N., et al. (2018) Factors Associated with Infant Feeding Practices and Nutritional Status among Children Aged 6-24 Months Attending Child Welfare Clinics in Kajiado Sub-County. East African Medical Journal, 93, 348-353.

[13] Saleh, F., Ferdous Ara, M., Hoque, A. and Alam, M.S. (2014) Complementary Feeding Practices among Mothers in Selected Slums of Dhaka City: A Descriptive Study. Journal of Health, Population, and Nutrition, 32, 89.

[14] Victora, C.G., Adair, L., Fall, C., Hallal, P.C., Martorell, R., Richter, L. and Sachdev, H.S. (2008) Maternal and Child under Nutrition: Consequences for Adult Health and Human Capital. The Lancet, 37, 340-357. https://doi.org/10.1016/S0140-6736(07)61692-4

[15] Santos, I., Victora, C.G., Martines, J., Gonçalves, H., Gigante, D.P., Valle, N.J. and Pelto, G. (2001) Nutrition Counseling Increases Weight Gain among Brazilian Children. The Journal of Nutrition, 131, 2866-2873. https://doi.org/10.1093/jn/131.11.2866

[16] Abdi, A.A. (2018) Complementary Feeding Practice and Associated Factors among Mother of Children Aged 6-23 Months in Agro-Pastoral Communities of Rural Gode District, Somali National Regional State, Eastern Ethiopia.

[17] Mutua, M.K. (2017) Patterns and Determinants of Breastfeeding and Complementary Feeding Practices in Urban Informal Settlements, Nairobi Kenya.

[18] Bégin, F. and Aguayo, V.M. (2017) First Foods: Why Improving Young Children's Diets Matter. Maternal \& Child Nutrition, 13, e12528. https://doi.org/10.1111/mcn.12528

[19] Rahman, A. and Akter, F. (2019) Reasons for Formula Feeding among Rural Bangladeshi Mothers: A Qualitative Exploration. PLoS ONE, 14, e0211761. https://doi.org/10.1371/journal.pone.0211761

[20] Berhane, H.Y., Ekström, E.C., Jirström, M., Berhane, Y., Turner, C., Alsanius, B.W. and Trenholm, J. (2018) Mixed Blessings: A Qualitative Exploration of Mothers' Experience of Child Care and Feeding in the Rapidly Urbanizing City of Addis Ababa, Ethiopia. PLoS ONE, 13, e0207685. https://doi.org/10.1371/journal.pone.0207685

[21] Government of People's Republic of Bangladesh, Ministry of Health and Family Welfare (2016) Health Bulletin 2016. Management Information System, Directorate General of Health Services, Mohakhali, Dhaka, 1212.

https://www.academia.edu/10431782/Government_of_the_Peoples_Republic_ofBan gladesh

[22] Monterrosa, E.C., Pelto, G.H., Frongillo, E.A. and Rasmussen, K.M. (2012) Constructing Maternal Knowledge Frameworks. How Mothers Conceptualize Complementary Feeding. Journal of Appetite, 59, 377-384. 
https://doi.org/10.1016/j.appet.2012.05.032

[23] https://bdnews24.com/bangladesh/2017/02/27/bangladesh-parliament-passes-law-allowi ng-child-marriage-in-special-circumstances\#: :text=Parliament\%20has\%20passed \%20the\%20child,it\%20in\%20'special\%20circumstances'.\&text=On\%20Monday\%2C \%20the \%20Child\%20Marriage,placed\%20it\%20before\%20the\%20MPs

[24] Salarkia, N., Amini, M., Abodollahi, M. and Eshrati, B. (2014) Nutrition Counseling Increases Weight Gain among Brazilian Children. The Journal of Nutrition, 131, 2866-2873. https://doi.org/10.1093/jn/131.11.2866

[25] Walsh, A., Kearney, L. and Dennis, N. (2015) Factors Influencing First-Time Mothers' Introduction of Complementary Foods: A Qualitative Exploration. BMC Public Health, 15, Article No. 939. https://doi.org/10.1186/s12889-015-2250-z

[26] Doub, A.E., Moding, K.J. and Stifter, C.A. (2015) Infant and Maternal Predictors of Early Life Decisions. The Timing of Solid Food Introduction. Journal of Appetite, 92, 261-268. https://doi.org/10.1016/j.appet.2015.05.028

[27] Lindsay, A.C., Machado, M.T., Sussner, K.M., Hardwick, C.K. and Peterson, K.E. (2008) Infant-Feeding Practices and Beliefs about Complementary Feeding among Low-Income Brazilian Mothers: A Qualitative Study. Food and Nutrition Bulletin, 29, 15-24. https://doi.org/10.1177/156482650802900102 